\title{
Algunas claves para la interpretación histórica de una fuente neotestamentaria judeo-cristiana: ¿Cuándo, por quién y por qué fue escrito el Apocalipsis?
}

CÉSAR VIDAL

\section{INTRODUCCIÓN ${ }^{1}$}

De entre los diferentes documentos históricos que componen el conjunto de obras a las que, convencionalmente, se denomina Nuevo Testamento, sin duda el de más difícil interpretación es el Apocalipsis, precisamente el que aparece consignado en último lugar. De manera esquemática, los diferentes intérpretes de la mencionada obra pueden agruparse en varios bloques bien concretos. En primer lugar, la denominada escuela preterista albergaría a aquellos autores que encajan el libro en un periodo ya pasado. De acuerdo con esta interpretación, que casi ha gozado de un carácter oficial en ciertos medios católicos, sostenida entre otros por el jesuita Alcázar en 1614, el Apocalipsis describiría la historia de la iglesia desde el siglo primero hasta el triunfo en la época de Constantino.

Las escuelas futuristas sostienen, por el contrario, que, a partir del capítulo 4 (o del 2, según el esquema), estaría describiendo un futuro lejano que, por regla general, se identifica con la época en que vive el intérprete en cuestión. Esta visión, cuyo gran precursor fue el jesuita Ribera (c. 1603), resultó absorbida por el dispensacionalismo del siglo pasado y hace acto de presencia con diversos matices en la hermeneútica de diferentes sectas

Sobre Apocalipsis y las diversas posturas, ver: T. ZaHN: Die Offenbarung des Johannes, 2 vols., Leipzig, 1924-6; W. HendRIKSEn: More than Conquerors, Londres, 1962; G. R. BeAsleyMurRAY: The Book of Revelation, Londres, 1974; R. H. MounCE: The Book of Revelation, Grand Rapids, 1977; G. QuIsPEL: The Secret Books of Revelation, Nueva York, 1979; F. SCHüssLeR FigRenzA: Invitation to the Book of Revelation, Grand Rapids, 1981. 
contemporáneas. El texto del Apocalipsis queda arrancado de su contexto histórico y proyectado, sin razón que lo explique suficientemente, hacia un futuro lejano para el autor pero inmediatamente cercano para el hermeneuta.

Finalmente, las escuelas historicistas han tendido a contemplar el libro como un intento de "desvelar» (de ahi Apocalipsis) la historia de la humanidad, desde una perspectiva cristiana, que se extiende desde el siglo primero hasta la Parusía. El contínuo avance hacia el futuro a partir de las condiciones presentes ha permitido a algunos autores elaborar interpretaciones coherentes y sólidas del libro sin referirlas necesariamente a personajes históricos concretos y limitándose a ver en sus descripciones paradigmas de todas las épocas ${ }^{2}$. En otros casos, se ha tendido a contemplar la obra como una serie de repeticiones continuadas en torno al mismo marco de hechos ${ }^{3}$, algo que la estructura septenaria del libro favorece de manera especial ${ }^{4}$.

Ciertamente, cada una de estas escuelas experimenta fragmentaciones internas de no pequeña envergadura pero, en su conjunto, vienen a resumir tres enfoques concretos de interpretación del libro. El mismo es visto como un relato de los primeros siglos del cristianismo que habría triunfado en el siglo IV con Constantino, como el relato de un mensaje incrustado en el lejano futuro o como una descripción de la historia desde el siglo primero hasta su consumación en la Segunda Venida de Cristo. Desde nuestro punto de vista, ninguno de esos enfoques, con sus distintos matices, recoge "stricto sensu" la perspectiva desarrollada por la trama del Apocalipsis. En las páginas siguientes intentaremos arrojar luz al respecto partiendo de tres puntos de partida diferentes: cuándo, quién y por qué fue escrito el Apocalipsis. El examen de los mismos podrá situarnos sobre un terreno más sólido a la hora de dibujar el esquema subyacente a esta obra.

\section{¿CUÁNDO FUE ESCRITO EL APOCALIPSIS?}

La datación del Apocalipsis continua siendo hoy cuestión abierta. La mayoría de los estudiosos la sitúa a finales del s. I, relacionándola con

\footnotetext{
2 En este sentido, ver especialmente: G. R. BeAsLEy-MurRay: The Book of Revelation, Londres, 1974.

3 Algo que no dista tanto, en nuestra opinión, de la perspectiva de Juan. En este sentido, ver W. Hendriksen: More than Conquerors, Londres, 1962; L. MorRis: The Revelation of St. John, Grand Rapids, 1979; J. GraU: Estudios sobre Apocalipsis, Barcelona, 1977.

4 En este sentido, ver: A. Yarbro Collins: "The Combat Myth in the Book of Revelation", en $H D R, 9,1976$, págs. 8-13 y 32-44; J. W. Bowman: The Drama of the Book of Revelation, Filadelfia, 1955.
} 
una supuesta persecución de Domiciano contra los cristianos. Tal interpretación resulta especialmente grata a los futuristas en la medida en que, supuestamente, permite arrojar hacia los siglos venideros el mensaje de la obra. Pese a todo, hoy existe una tendencia progresiva a desplazar tal datación a un período situado en los sesenta, cerca de la persecución neroniana. La primera tesis se ha sustentado fundamentalmente en el hecho de que Ireneo, escribiendo hacia el $180 \mathrm{~d}$. de C. en relación con la Bestia de Ap 13, 18, la identificó con Domiciano (Adv. Haer V, 30, 3). El pasaje es mencionado por Eusebio en dos ocasiones (HE III, 18, 2 ss y V, 8, 6) si bien no parece desprenderse ineludiblemente que éste situara la redacción de Apocalipsis en la época de Domiciano, aunque fija durante ese reinado el destierro de Juan a Patmos, identificando a éste con el apóstol, al igual que Victorino (In Apoc $X, 11$ ). Todo esto implicaría que Juan, el autor de Apocalipsis, y Juan, el del cuarto Evangelio, son la misma persona; que ambos coinciden con el apóstol Juan; y que el Apocalipsis fue «visto» durante el reinado de Domiciano.

Clemente de Alejandría (Quis div. salv.? XLII, 1-15) ciertamente nos habla de que Juan, el autor de Apocalipsis, fue liberado de Patmos a la muerte del "tirano", pero en ningun momento identifica a que personaje se refiere con este calificativo. Algo similar sucede con Orígenes (In Matt XX, 22), que nos habla de la condena de Juan a Patmos pero no la situa bajo ningun monarca concreto. Por el contrario, Tertuliano - al igual que Hipólito (De Chr. et Antichr. XXXVI) señala que Juan estaba en Roma cuando fue desterrado y de ello parece desprenderse que el hecho tuvo lugar bajo el principado de Nerón (Paersecr, XXXVI, 3). Al menos, así lo interpretó Jerónimo (De vir. ill. IX).

Epifanio (Adv. Haer, XLI, 12 y 33) sitúa el destierro de Juan en el reinado de Claudio César, si bien - cabe al menos la posibilidad- seguramente confundió a Nerón con Claudio como consecuencia de que el primero también tenía ese nombre. En cuanto a la versión siríaca de Apocalipsis ${ }^{5}$ y a la Historia de Juan, el hijo de Zebedeo en siríaco señalan que fue Nerón el que ordenó el destierro de Juan. Aparentemente pues, las noticias patrísticas acerca del período de datación de la obra están divididas en cuanto a relacionarlo con el de Nerón o el de Domiciano.

5 J. GWYNN (ed.): The Apocalypse of St. John in a Syriac Version hitherto Unknown, Dublín, 1897, 1; y G. M. LAMSA: Holy Bible from the Acient Eastern Text, Nueva York, 1968, págs. 1.2251.243. 
En realidad, el análisis de las fuentes antiguas resulta descorazonador a la hora de encontrar evidencias de una persecución imperial contra los cristianos durante el reinado de Domiciano. Suetonio, que residió en Roma, durante la mayor parte de este reinado no menciona nada al respecto y Plinio, que a la circustancia anterior une la de haber formado parte del senado, señalaría después su ignorancia acerca de los cristianos y de cómo tratarlos de acuerdo con el derecho del Imperio (Ep. X, 96). La idea de una gran persecución de Domiciano brilla de hecho por su ausencia en la obra de este autor.

Algo similar encontramos en los testimonios patrísticos. Tertuliano -en un testimonio reflejado por Eusebio (HE IV, 20,7)-parece admitir que, bajo Domiciano, se tomaron algunas medidas aisladas contra algunos cristianos, pero las mismas se limitaron al destierro y concluyeron en breve tiempo con el perdón de los condenados (Apol V). Eusebio (HE III, 17-20) hace referencia a una persecución contra los cristianos en la época de Domiciano pero es incapaz de mencionar el nombre de uno solo de los mártires e incluso la referencia a Domitila y de Flavio Clemente está plagada de errores (señala que éste último fue desterrado en lugar de ejecutado como dice Suetonio (Domiciano XVI) y afirma que Domitila era sobrina de Flavio Clemente cuando de hecho era esposa de Clemente y sobrina de Domiciano). Por otro lado, parece que el caso de Domitila estuvo más relacionado con razones políticas que religiosas ${ }^{6} \mathrm{y}$ además Eusebio partía de Melitón de Sardis, que, muy posiblemente, inventó la existencia de una persecución bajo Domiciano con la finalidad de mostrar que sólo los "malos emperadores" habían perseguido a los cristianos?.

En realidad, la calificación de Domiciano como el emperador bajo el cual tuvo lugar "la más cruel persecución en todo el mundo» no se produjo hasta el s. V con Orosio (Hist. adv. pag VII, 10,1). Este conjunto de aspectos, que hemos reseñado someramente, hacen que, a nuestro juicio, resulte muy difícil de aceptar la idea de situar una persecución -y más, generalizada - contra los cristianos en la época de Domiciano ${ }^{8}$. Por 10

${ }^{6}$ B. REICKE (ed.): Neues Testament und Geschichte; Oscar Cullman zum 70 Geburtstag, Zurich y Tubinga, 1972, pp. 43-67.

7 T. D. BARNES: “An Apostle on Trial» en Journal of Theological Studies, 20, 1969, pp. 407-19.

8 En el mismo sentido: P. Richardson: Israel in the Apostolic Church, Cambridge, 1969, pp. 40 y ss.; R. L. MILBURN: "The persecution of Domitian", en Christian Quarterly Review, 139, 1945, pp. 154-64; J. KNUDSEN: "The Lady and the Emperor" en Church History, 14, 1945, pp. 17-32; W. H. C. FREND: Martyrdom and Persecution in the Early Church, Oxford, 1955, pp. 212-7; G. E. M. DE STE CRoIx: "Why were the Early Christian persecuted? en Past and Present, 26, 1963, pp. 6-38; B. Newman: "The fallacy of the Domitian Hypothesis" en New Testament Studies, 10, 1963-4, pp. 
tanto, difícilmente podría situarse en su reinado el ambiente del que surgió el Apocalipsis.

Por el contrario, el contexto que deja traslucir el libro sí parece que encajaría en el clima de la persecución neroniana. Para empezar, la persecución descrita en el mismo se limita a la ciudad de Roma (Ap 13, 14-17) y no se extiende a las provincias (Ap 1-2), circustancias ambas que, como en su día señaló Sherwin-White ${ }^{9}$, armonizan perfectamente con lo que sabemos acerca de este evento. El mismo libro $(13,8)$ indica además cuál es el nombre de la Bestia mediante un ingenioso recurso a la gematría. El mismo aparece como 666, es decir, la suma de las letras en hebreo 10 arameo) para Nerón César. Tal identificación ha sido confirmada por los hallazgos de Qumran ${ }^{10}$ y tiene paralelos en Suetonio (Nerón XXXIX) quien nos dice que se practicaba un curioso juego gemátrico con Nerón cuyo nombre en griego sumaba 1005 , es decir, lo mismo que «mató a su madre", una referencia a un crimen del emperador-y en Filostrato (Vi. Apol IV, 38) donde a Nerón se le denomina la «bestia».

Por otro lado, la descripción de la Bestia encaja con Nerón en otros aspectos. En primer lugar, está la referencia a la herida de espada de la Bestia posiblemente relacionada con el suicidio del emperador. Tenemos además las noticias relacionadas con la estatua o imagen de la misma (Ap 13, 4, 12-15; 14, 9-11; 15, 2; 16, 2; 19, 20; 20,4) que, fácilmente, podría identificarse con el episodio acerca de Nerón descrito por Tácito en Ann XIII, $8^{11}$.

Ap 17, 9-11 contribuye a confirmar este punto de vista. Según este pasaje, Roma ha tenido ya cinco reyes, otro está reinando, y otro tiene que venir por un período muy breve. Una vez más, los datos encajan con el

133-9 y T. D. BARNES: Tertullian, Oxford, 1971, pp. 143-63. Un punto de vista contrario en L. W. BARNARD: "Clement and the persecution of Domitian", en New Testament Studies, 10, 1963-4, pp. 251-60.

9 A. N. SHERWIN-WHITE: «Early Persecutions and Roman Law again" en Journal of Theological Studies, 3, 1952, p. 202. Esto choca con el testimonio de Tertuliano (Apol V, 3) 一sólo corroborado por Sulpicio Severo (Ad. nat, 1, 7, 9) - en relación con el supuesto "institutum Neronianum", pero resulta discutible la veracidad del aserto de Tertuliano. Un estudio muy completo del tema con abundante bibliografia en A. SCHNEIDER: Le premier livre ad Nationes de Tertullien, Neuchátel, 1968, pp. 171-3.

${ }_{10}$ P. BenoIT, J. T. Milik y R. DE VAux (eds.): Discoveries in the Judaean desert of Jordan, II, Oxford, 1961, p. 18, lámina 29. La lectura alternativa 616 -que ya mencionó Ireneo en Adv. haer. $V, 28,2-$ encaja con la forma latina "Nero Caesar" y con la griega "Kyrios Kaisar". Sobre este último aspecto ver: O. Cullman: El Estado en el Nuevo Testamento, Madrid, 1966, pp. 87 y ss. LXII, V, II.

1 Una confirmación de las pretensiones de culto por parte de Nerón en Dión Casio, Hist., 
período al que hacemos referencia. Los reyes ya pasados serían 1. Augusto, 2. Tiberio, 3. Calígula, 4. Claudio y 5. Nerón. Galba correspondería al sexto (reinó de Junio del 68 a Enero del 69) y Otón al séptimo que había de durar poco (de hecho, de enero a abril del 69).

En relación con el contexto judío de la obra, resulta asimismo evidente que no se ha producido una ruptura absoluta entre cristianismo y judaísmo (aunque ya se producen indicios de la misma, vg: Ap 2, 9 y 3, 9) y que la esperanza de la Parusía es patente (Ap 2, 25). Sin duda, ha comenzado la guerra judía, pero el templo no ha caido aún del todo en manos de los romanos (Ap 11, 1 ss.) ni tampoco la ciudad en que se crucificó a Jesús, el Señor $(11,8$ y 18, 10). Los miembros del pueblo de Dios ( $¡$ al que se identifica con Israel y no con una nueva entidad espiritual!) han experimentado persecución en Jerusalén (Ap 11, 7 ss.) y han huido de la ciudad en un intento de ponerse a salvo (Ap 12, 1 ss.) (algo que recuerda las advertencias de Jesús en los denominados apocalipsis sinópticos y que excluye, siquiera indirectamente, que los judeo-cristianos se identificaran con los zelotes que la defendian). Con todo, desde el punto de vista del autor, la suerte del templo ya está echada. Había sido medido —un símbolo veterotestamentario para indicar lo irreversible del juicio divino (2 Re 21,13 ; Is 34, 11; Lam 2, 8; Am 7, 7-9 y especialmente Ez 40-45 vg: 44, 23 y 43, 710) - y sería arrasado.

Este conjunto de evidencias, principalmente el hecho de que las fuentes más primitivas no identificaran al emperador que desterró a Juan con Domiciano o incluso lo hicieran con Nerón, ha llevado a diversos autores a situar la redacción de Apocalipsis entre la muerte de Nerón en el 68 y la caída de Jerusalén en el 70. Esa fue la postura de T. Zahn ${ }^{12}$, A.S. Peake ${ }^{13}$, E.B. Allo ${ }^{14}$, J.B. Lightfoot ${ }^{15}$, B.F. Westcott ${ }^{16}$, e incluso F. Engels ${ }^{17}$. Tal punto de vista se ha visto sometido a un cambio de posición radical en nuestro siglo por parte de algunos teólogos ${ }^{18}$, aunque no ha sucedido lo mismo en el terreno de la ciencia histórica. B.W. Henderson situó el

12 T. ZAHN, Introduction..., III, 201 ss.

13 S.D. PEAKE, The Revelation of John, Londres, 1919, pp. 71-7.

14 E.B. Alto, L'Apocalypse, París, 1933 (3), CCXXII-CCXXIX.

15 J.B. LIGHFOOT, “Biblical Essays" en Lectures of 1867-72, Londres, p. 52 e Idem, Essays on he Work entitled Supernatural Religion, Londres, 1889, p. 132.

16 B.F. WESTCOTT, The Gospel according to St John, Londres, 1882, LXXXVII.

17 Me estoy refiriendo de manera especial a su "Sobre la historia del cristianismo primitivo" en K. Marx-F. Engels, Sobre la religión, Salamanca, 1979, pp. 403 ss. y que, originalmente, apareció en la revista Neue Zeit, I-1-2, 1894-5, pp. 4-13 y 36-43.

18 Una opinión curiosa en J. Massyngberde Ford, Revelation, New York, 1975, que situa al Apocalipsis antes del ministerio público de Jesús. 
Apocalipsis en la época de Nerón ${ }^{19}$ y volvió a sustentar años después el mismo punto de vista ${ }^{20}$. En el mismo sentido, se expresaron $G$. Edmunson ${ }^{21}$, A.D. Momigliano ${ }^{22}$, A. Weigall ${ }^{23}$ y K.A. Eckhardt ${ }^{24}$. Más recientemente, aunque con ciertas matizaciones, ha defendido esta misma posición $\mathrm{Ch}$. Rowland ${ }^{25}$.

Desde una perspectiva histórica, efectivamente el punto de vista expresado por estos autores es el más razonable. Los datos anteriores obligaban a fijar la fecha de redacción de la obra en algun punto a finales del año 68. Desde esa perspectiva, sería incluso posible identificar las diversas cabezas de la "bestia". Galba - como indicaría 17, 10- estaría en el trono, Nerón habría muerto a espada hacía poco, y podría creerse que la misma Jerusalén - donde habían sido asesinados Jesús (Ap. II, 8) y algunos de sus seguidores (Ap 17,6) - acabaría pereciendo frente a las hordas romanas, siendo su templo arrasado. Con ello, se cumpliría así el juicio de Dios contra los perseguidores de los discípulos de Jesús.

La conciliación de esta tesis con las fuentes que relacionan el encarcelamiento de Juan con el gobierno de Domiciano resulta, por otra parte, muy sencilla. A mitad del año $70 \mathrm{~d}$. de $\mathrm{C}$. Vespasiano se hallaba en Alejandria, mientras su hijo mayor, Tito, sitiaba Jerusalén. Su hijo menor, Domiciano, fue nombrado César y utilizó la residencia imperial (TÁcITo, Hist IV, 2 y SUETONıO, DOMICIANO, I); se le invistió del «imperium consulare» y se escribió su nombre en el encabezamiento de edictos y despachos (TÁCITO, Hist IV, 3 y DIÓN CASIO, Hist, LXV, 2, 1 ss.). En ese período - tal y como indica Tertuliano- un profeta judeo-cristiano llamado Juan habria sido condenado por Domiciano al destierro en Patmos. En junio, Domiciano abandonó Roma y en el 71 Vespasiano tomó como colega a Nerva y, quizá, en este período de tiempo Juan fue liberado. De ser cierta esta hipótesis ${ }^{26}$, Juan habría sido condenado por Domiciano y liberado por Nerva (como afirma la tradición) pero en el 70-1 y no durante el período de reinado de aquel. Para entonces, su obra ya estaría escrita desde

20 B.W. Henderson, Five Roman Emperors, Cambridge, 1927, pp. 164-79.

21 G. Edmundson, The Church in Rome, Londres, 1913, pp. 164-79.

22 A. Momigliano, Cambridge Ancient History, X, Cambridge, 1934, p. 726.

23 A. Weigall, Nerón, París, 1950.

24 K.A. EсKнаRDT, Der Tod des Johannes, Berlin, 1961, pp. 58-72.

$25 \mathrm{CH}$. Rowland, The Open Heaven, Londres, 1985, pp. $403 \mathrm{ss.}$

26 Ha sido ya mencionada por W.H. SImCox, Revelation, Cambridge, 1893, L-LI y E.C. SELWYN, Authorship of the Apocalypse, Cambridge, 1900, pp. 94-6 e Idem, The Christian prophets and the Prophetic Apocalypse, Cambridge, 1900, pp. 120-2. 
hacía tiempo ${ }^{27}$. Esta solución que proponemos es, a nuestro juicio, la única que permite hacer justicia a los diferentes datos que nos proporcionan tanto la evidencia interna como externa del libro en torno a su fecha de redacción. La misma se habría producido entre el 68 y el 70 d. de C., si bien antes de la caída de la ciudad de Jerusalén.

Resumiendo, puede afirmarse que Apocalipsis fue escrito antes del 70 d. de C. porque en la citada obra:

I. La actitud hacia el Imperio es negativa tras la persecución neroniana del 65 d. de $\mathrm{C}^{28}$. Roma es la "Bestia" que será juzgada por Dios (Ap. 6, 9 ss.; $16,6 ; 17,6 ; 18,20,24 ; 19,2 ; 20,4)$. Por el contrario, esta visión no se corresponde con lo que sabemos acerca de Domiciano ya que resulta evidente que bajo su gobierno no se produjo ninguna persecución contra los cristianos. De hecho, Suetonio, que residió en Roma, durante la mayor parte de este reinado no la menciona; Plinio no sabía nada acerca de los cristianos ${ }^{29}$; Tertuliano la desconoce ${ }^{30} \mathrm{y}$ el relato de Eusebio ${ }^{31}$ es claramente legendario y erróneo. En realidad, la idea de que bajo Domiciano se produjo «la más cruel persecución en todo el mundo" no aparece hasta el s. V con Orosio ${ }^{32}$.

II. La Bestia es Nerón, en sentido estricto, y el poder romano, en sentido amplio.

En Apocalipsis 13, 8, se afirma que el nombre de la Bestia es 666, es decir, la suma del valor númerico de las letras en hebreo (o arameo) para Nerón César. Tenemos paralelos de esto en Qumran ${ }^{33}$,

27 Incluso se ha formulado la hipótesis de que en parte lo hubiera sido antes del destierro y de que mensajes similares a los contenidos en la misma fueran la causa de su conena. Este es el punto de vista de SELWYN, Christian prophets..., pp. 212-21 que mantenia que Apocalipsis 4-22 se habia escrito en Roma bajo Galba en el 68-9 y que habia provocado la condena del autor por Domiciano a inicios del 70 a la isla de Patmos. Allí habría escrito el autor 1-3 como una carta enviada a las iglesias de Asia Menor. No es imposible esta teoria pero tenemos que admitir que la continuidad del c. 1 con 4 , y ss. y la afirmación de 17, 10 se alzan como inconvenientes contra la misma.

${ }_{28}$ En relación con el tema, con bibliografía referente a las diversas cuestiones relacionadas, ver: P. LABRIOLLE, La Réaction paínne, París, 1948 ( $2^{\mathrm{a}} \mathrm{ed}$.); M. SORDI, Los cristianos y el Imperio romano, Madrid, 1988, pp. 29 ss.; C.P. THIEDE, Simon Petr, Grand Rapids, 1988, pp. 185 ss.; P. FERnANDEZ URIEL, "El incendio de roma del año 64: Una nueva revisión crítica” en Espacio, Tiempo y Forma, Serie II, Historia Antigua, t. 3, Madrid, 1990, pp. 61-84.

29 Ep. X, 96.

30 Apol. V. Eusebio lo menciona en HE IV, 20, 7.

31 HE III, 17-20.

32 Hist. adv. pp. VIII, 10,1.

33 P. BENOIT, J.T. MILIK y R. DE VAUX (eds), Discoveries in the Judaean desert of Jordan, II, Oxford, 1961, p. 18, lámina 29. La lectura alternativa 616 - que ya mencionó Ireneo en Adv. haer. 
Suetonio ${ }^{34}$-quien nos dice que se practicaba un curioso juego gemátrico con Nerón cuyo nombre en griego sumaba 1005, es decir, 10 mismo que "mató a su madre", una referencia a un crimen del emperador-y Filostrato ${ }^{35}$ donde a Nerón se le denomina la "bestia".

De hecho, el libro contiene referencias muy explícitas en relación con el mencionado emperador que sólo pueden quedar oscurecidas o por la ignorancia de la historia del s. I d. de C., o por la insistencia en identificar a la Bestia con un personaje futuro. Así, se nos dice que la Bestia fue herida a espada (posiblemente una referencia al suicidio del emperador); que tenía una estatua o imagen (Apoc. 13, 4, 12-15; 14, 9-11; 15, 2; 16, 2; 19, $20 ; 20,4)$ que, fácilmente, podría identificarse con el episodio acerca de Nerón descrito por Tácito en Ann XIII, $8^{36}$, etc.

Esta interpretación permite además identificar las diversas cabezas de la "bestia" con relativa facilidad. Galba (Apoc. 17, 10) estaría en el trono, Nerón habría muerto a espada hacía poco, y la Jerusalén que había rechazado a Jesús y en cuyo recinto éste había sido ejecutado acabaría pereciendo frente a las legiones romanas, siendo su templo arrasado ${ }^{37}$.

III. La obra evidencia que todavía no se ha producido una ruptura total entre cristianismo y judaísmo, aunque ya se producen indicios de la misma, vg: Ap. 2, 9 y 3, 9). De hecho, Jerusalén es denominada la "gran ciudad" (Apocalipsis 11, 8), Babilonia (Apocalipsis 18, 9) y Sodoma (Apoc. 11, 8. comp. con Isaías 1, 9-10), como símbolo de su presunta apostasía. El autor de Apocalipsis invita a los judeo-cristianos aún relacionados con ella a que la abandonen (Apocalipsis 18,4).

Por otro lado, debe tenerse en cuenta que en la obra se anuncian una serie de calamidades que han de caer sobre "la tierra", término que no se refiere al planeta, sino que tiene el significado propio del Antiguo

\footnotetext{
V, 28, 2- encaja con la forma latina "Nero Caesar" y con la griega "Kyrios Kaisar". Sobre este último aspecto ver: O. Cullmann, El Estado en el Nuevo Testamento, Madrid, 1966, pp. 87 ss.

${ }^{34}$ Nerón, XXXIX.

35 Vit. Annl, IV, 38.

${ }^{36}$ Una confirmación de las pretensiones de culto por parte de Nerón en Dión Casio, Hist., LXII, V, II.

${ }^{37}$ Existe otra alternativa a la fecha mencionada que desplazaria unos años la misma. Consistiria ésta en pensar que el saqueo de Roma encja mejor con la descripción de Babilonia caida que el incendio del 64 y que la cercania de las legiones romanas al área del templo es la acaecida en los primeros meses del 70 y no durante el 68. En cualquier caso, y a efectos de nuestro estudio, que sea la hipótesis expuesta en el cuerpo de la obra o esta alternativa la más cercana a la realidad no creemos que varie sensiblemente las conclusiones que expondremos en la segunda parte del libro.
} 
Testamento: la tierra de Israel, el Erets Israel. Un simple análisis comparativo de las plagas del Apocalipsis con el relato de Josefo sobre la guerra del 66-73 d. de C. muestra una serie de coincidencias entre la secuencia de hechos y catástrofes que cuesta verlas como casuales.

IV. El Templo de Jerusalén no ha caido.

En Apocalipsis, la guerra judía del 66 d. de C., seguramente, se ha iniciado pero el templo no ha caído aún del todo en manos de los romanos (Ap. 11, 1 ss.) ni tampoco la ciudad en que se crucificó a Jesús, el Señor $(11,8$ y 18,10$)$. Pese a todo, el templo había sido medido - un símbolo veterotestamentario para indicar su condena ${ }^{38}-y$, como consecuencia, sería arrasado. En cuanto a los miembros del pueblo de Dios han sido perseguidos en Jerusalén (Ap. 11, 7 ss) y han huido de la ciudad (Ap. 12, $1 \mathrm{ss}$.). Este pasaje, muy posiblemente, hace referencia a la marcha de los judeo-cristianos de la ciudad a Pella ${ }^{39}$ para no intervenir en el levantamiento zelote, y presenta claros paralelos con los oráculos de Jesús acerca de la destrucción futura del Templo (Mateo 24, 15 ss.; Marcos 13, 14 ss.; Lucas 21, 20 ss.).

Lejos de proyectarse hacia un futuro lejano, el autor de Apocalipsis fija su mente, de manera predominante, en acontecimientos que tienen lugar en su más tangente contemporaneidad y en otros que anuncia que se producirán $-\mathrm{y}$, efectivamente así fue- en breve.

\section{¿QUIÉN ESCRIBIÓ APOCALIPSIS?}

Este encuadre cronológico al que hemos hecho referencia viene, siquiera en parte, respaldado por los testimonios acerca de la redacción del libro. Lo que la obra nos dice acerca de su redactor no es mucho. Se trata de un profeta llamado Juan $(1,4$ y $9 ; 22,8)$, al que se ha deportado a Patmos por predicar el Evangelio. También parece que el autor tenía cierto prestigio entre las siete iglesias de Asia Menor (Apocalipsis 2-3) a las que dirige sendas cartas al principio de la obra. Estaba asimismo muy bien informado de la guerra contra Roma entre el $66 \mathrm{~d}$. de C. y el $68 \mathrm{~d}$. de c. Sin embargo, todos estos datos no terminan de aclararnos qué Juan escribió Apocalipsis. Identificarlo con el autor del Evangelio plantea sobre

\footnotetext{
382 Reyes 21, 13; Isaías 34, 11; Lamentaciones 2, 8; Amós 7, 7-9 y especialmente Ezequiel $40-45$ (vg: 44,23 y $43,7-10)$.

39 Sobre la historicidad de este episodio, véase: C. Vidal, El judeo-cristianismo...
} 
todo problemas lingüísticos porque ambas obras tienen estilos y lenguajes muy diversos.

Pese a todo, Apocalipsis presenta curiosos puntos de contacto con términos propios del Evangelio de Juan. Entre ellos se puede mencionar que el Hijo es llamado el Verbo (Juan 1, 1-3; Apocalipsis 19, 13; también I Juan 1,$1 ; 5,7)$ que se le identifica con el Cordero de Dios (Juan 1, 29-36; Apocalipsis 14, 4, etc); que se le tributa la misma honra que a Dios Padre (Juan 5, 23; Apoc 5, 13); que se le identifica con el YHVH del Antiguo Testamento (Juan 12, 36-41 con Isaias 6, 10; Apocalipsis 1, 11-13 y 22, 13 con Apocalipsis 1, 8 e Isaías 41,4 y 44,6); que se habla de Su victoria ligada a la de los que le siguen (un factor en común con las Epístolas vg: Juan 16, 33 y I Juan 5, 4; Apocalipsis 12, 11), etc.

Casi con toda seguridad el autor de Apocalipsis formaba parte de una especie de "escuela teológica" que giró en torno al autor del Evangelio de Juan, quizá incluso pueda ser identificado con un personaje denominado Juan el anciano al que se menciona en alguna fuente patrística, pero es difícil que podamos avanzar más en el proceso de averiguar su personalidad de manera indiscutible. Se trata de un autor del siglo primero sumergido en el remolino de la persecución imperial algo que, nuevamente, nos apunta hacia un contexto neroniano.

\section{¿PORQUÉ SE ESCRIBIÓ EL LIBRO DE APOCALIPSIS?}

La tercera clave de clarificación del libro gira en torno a las razones que impulsaron a escribir el libro. Tratar el tema en profundidad desborda las características del presente trabajo pero sí podemos señalar algunas líneas maestras. Obviamente, los destinatarios de la obra son, principalmente, iglesias de Asia Menor (c. 1-3). Las mismas, lejos de tener un contenido simbólico, son comunidades reales del siglo primero como lo demuestra la descripción minuciosa de episodios de la época ${ }^{40}$. A estas se les anuncian no acontecimientos proyectados hacia el futuro lejano de siglos sino "las cosas que deben acontecer pronto» $(1,1)$ "porque el tiempo está cerca" $(1,3)$.

El final de los años sesenta del siglo primero resultó especialmente angustioso para los cristianos. Por un lado, el Imperio los había colocado en

40 Un estudio irrefutable $e$ indispensable al respecto en W.M. RAMSAY, The Letters to the Seven Churches, Peabody, 1994. 
su punto de mira como adversarios sometiéndolos a la primera persecución de envergadura hasta la fecha. Por otro, la comunidad judía de la que habian surgido se enfrentaba con las armas contra Roma. El primero los perseguía, la segunda optaba por una trayectoria que no podian seguir. ¿Podría sobrevivir el reducido colectivo frente a un Imperio enemigo y una comunidad a la que no podian unirse en su lucha armada? Esa es la gran pregunta que surca la práctica totalidad de las páginas del Apocalipsis.

Partiendo de ese contexto, fundamentalmente, la obra persigue alentar a esos cristianos de Asia Menor ubicados en medio de una situación convulsiva de persecución apenas acabada a la que se ha sumado el presumible final del Segundo Templo de Jerusalén (11), la ciudad donde murió Jesús $(11,8)$. La comunidad cristiana, lejos de sentir miedo, ante unos acontecimientos que se extienden aterradores inmediatamente detrás y delante, no debe temer sino perseverar. El futuro próximo se revelará muy distinto del amenazador presente $(1,1-3)$. Los rebeldes zelotes $\mathrm{ni}$ son el verdadero Israel ni vencerán a sus adversarios romanos (11). La dinastía julio-claudia, caracterizada por su deseo de auto-deificación, no sobrevivirá pese a su dominio ahora universal (13).

En las sugestivas páginas del Apocalipsis, y dentro de la tradición profética de Israel, Juan anunció una serie de juicios inmediatos contra diversas naciones (Roma e Israel, especialmente). A la vez, y de nuevo aquí el paralelo de Juan con los profetas de Israel es muy marcado, proyectó a sus lectores hacia una esperanza escatológica más lejana, ligada a la Parusía y consumadora de la Historia. El presente (descripciones relativamente fáciles de reconocer acerca de Roma e Israel) permite encuadrar la obra en un contexto histórico exacto y descubrir el juicio que del mismo tenían los primeros cristianos. El futuro, sirve al autor del escrito para mostrar a sus lectores como la historia actual tendrá similitudes con la del futuro, pero, entonces, ligada a la victoria final del Mesias. Apocalipsis, por lo tanto, ni es un libro en el que se describe la gloria del constantinismo ni tampoco una guía para especulaciones catastrofistas. Se trata de un documento de esperanza en que el autor pretende tranquilizar a una minoría perseguida y marginada, humillada y ofendida, apuntando fundamentalmente a hechos cercanos, aunque sin olvidar el esquema judio de una consumación de la Historia en algun momento del futuro. Si aceptamos tal perspectiva, Apocalipsis nos aparece como una lectura del presente (los capítulos 1-3 son buena muestra de ello) -un presente que podía volverse terriblemente cruel para los judeo-cristianos como lo había demostrado la persecución de Nerón-, pero que permitía interpretar el futuro. Sucediera lo que sucediese en el mismo, la última palabra estaría en manos de Dios y de Su Mesías. 
La visión de Juan en relación con el futuro cercano se mostró sorprendentemente lúcida y exacta. Presumiblemente, el autor de Apocalipsis, tras recuperar su libertad, marchó a Asia Menor donde se estableció y ocupó un papel de importancia en las iglesias de la zona. La estructura críptica de la obra - algo lógico teniendo en cuenta que se expresaba sobre el Imperio en términos nada elogiosos- explica que ya c. 180 Ireneo no supiera el significado del 666, y que la Oda 22 de las Odas de Salomón hubiera ya identificado al monstruo de siete cabezas con el mismo Satanás. Pese a su exactitud descriptiva, pese a su meticulosa narración de acontecimientos de especial importancia para las comunidades cristianas de Asia Menor en el siglo primero, en los siglos siguientes la obra se convertiría en un cajón de interpretaciones disparatadas. Sin embargo, pese a esos dislates hermeneuticos, la interpretación futura de Apocalipsis sería todo menos infecunda. El mensaje de que algun dia, tras una persecución generalizada de los discípulos de Jesús peor que la neroniana y llevada a cabo por alguien del que Nerón era un tipo, tendria lugar la Parusía y con ella la conclusión adecuada de la historia, no dejaría de resultar estimulante, generación tras generación, para comunidades cristianos enfrentadas conflictivamente con el poder civil. 